\title{
PREVALENCE OF IMPAIRED FASTING GLUCOSE IN ADULT POPULATION ATTENDING MEDICINE OUTPATIENT DEPARTMENT AT GVMCH
}

\author{
S. P. Kumaresan ${ }^{1}$, D. Anbarasu², B. Gowrishankar ${ }^{3}$, P. S. Ramesh ${ }^{4}$, R. Aswinth ${ }^{5}$, S. Aravinda Kumar 6 \\ ${ }^{1}$ Associate Professor, Department of Medicine, Government Vellore Medical College. \\ ${ }^{2}$ Associate Professor, Department of Medicine, Government Vellore Medical College. \\ ${ }^{3}$ Assistant Professor, Department of Medicine, Government Vellore Medical College. \\ ${ }_{4}^{4}$ Assistant Professor, Department of Medicine, Government Vellore Medical College. \\ 5 Postgraduate, Department of Medicine, Government Vellore Medical College. \\ ${ }^{6}$ Postgraduate, Department of Medicine, Government Vellore Medical College.
}

\section{BACKGROUND}

ABSTRACT

To determine the prevalence of impaired fasting glucose in adult population attending medicine outpatient clinic at Government Vellore Medical College, Vellore and correlate with risk factors.

\section{MATERIALS AND METHODS}

Adult population aged more than 30 years attending outpatient clinic at medicine department were randomly assessed for presence of impaired fasting glucose according to ADA criteria 2016 and related for presence of risk factors like age, weight, body mass index, waist circumference, and waist-hip ratio.

\section{RESULTS}

Totally, 985 subjects were studied. This included 496 (50.3\%) males and 489 (49.6\%) females. The prevalence of impaired fasting glucose in the Vellore population attending medicine OPD was found to be $15 \%$. The prevalence of impaired fasting glucose among male subjects were found to be $17 \%$ and among female subjects were $13 \%$. The prevalence of impaired fasting glucose was higher among both the male and female subjects with higher waist-hip ratio and BMI $>25$. Only female subjects with increased waist circumference had increased prevalence of impaired fasting glucose and not male subjects.

\section{CONCLUSION}

This study revealed that the prevalence of impaired fasting glucose in Vellore population is high (15\%) and is an under-diagnosed condition. The traditional risk factors like body mass index, waist-hip ratio are good predictors for development of diabetes mellitus in the Vellore district. But waist circumference can only predict among female population.

\section{KEYWORDS}

Type 2 Diabetes Mellitus, Impaired Fasting Glucose.

HOW TO CITE THIS ARTICLE: Kumaresan SP, Anbarasu D, Gowrishankar B, et al. Prevalence of impaired fasting glucose in adult population attending medicine outpatient department at GVMCH. J. Evolution Med. Dent. Sci. 2016;5(86):6412-6415, DOI: $10.14260 /$ jemds/2016/1450

\section{BACKGROUND}

Pre-diabetes is a state which is considered as an important risk factor and precursor for development of diabetes mellitus. ${ }^{1}$ Pre-diabetes state includes presence of either impaired fasting glucose or impaired glucose tolerance singly or in combination. ${ }^{1,2}$ In the statement released by ADA 2012, they were reclassified as "categories of increased risk for diabetes". ${ }^{3}$

The prevalence of impaired fasting glucose is common and underdiagnosed in most population. 4 There is increase in prevalence due to modern lifestyle and food habits. 5 The reported prevalence varies among population with different ethnic background.5,6 Currently, 314 million population were affected by impaired fasting glucose which would reach 500 million by $2025 .{ }^{7}$

Financial or Other, Competing Interest: None.

Submission 06-10-2016, Peer Review 18-10-2016,

Acceptance 21-10-2016, Published 27-10-2016.

Corresponding Author:

Dr. S. P. Kumaresan,

\#17, Chandrasekaran Street,

Shenbakkam, Vellore-8.

E-mail: drspk1962@gmail.com, aswinth.r@gmail.com

DOI: $10.14260 /$ jemds/2016/1450
It is estimated that $70 \%$ of impaired fasting glucose population would develop diabetes any time in life. ${ }^{8}$ The rate of development of diabetes was twice, when both impaired fasting glucose and impaired glucose tolerance is present. ${ }^{8}$

Many studies show occurrence of cardiovascular events is higher among pre-diabetic population.9,10 So by studying prevalence of impaired fasting glucose among Vellore population, early intervention can be planned for prevention of those cardiovascular complications among pre-diabetics. ${ }^{11}$

Impaired fasting glucose is a state where fasting blood glucose ranges above normal but below the range to be labelled as diabetes. According to American Diabetes Association 2016, impaired fasting glucose can be diagnosed when fasting plasma glucose value is between 100-125 $\mathrm{mg} / \mathrm{dL}$ [5.6-6.9 mmol/L]. ${ }^{12}$

Many studies shows progression of prediabetes to type II diabetes occurs at rate of $2 \%$ to $22 \%$ per year depending on the population studied. ${ }^{8}$ Among those, 50\% remain prediabetic and $25 \%$ revert to normal. ${ }^{8}$ In an 11-year followup study among adults with prediabetes in Mauritius, $46 \%$ developed diabetes, 28\% remained unchanged, and 26\% reverted to normal.8,13 Hence, this group is an important 
target for vigorous intervention for primary prevention of diabetes.

\section{Importance of Pre-diabetes in India}

The prevalence of impaired fasting glucose and progression to diabetes continues to increase in Indian population. The diabetes related morbidity and mortality have already emerged as major public health problem in India. ${ }^{14}$ Diabetes related damage in microvascular circulation can lead to retinopathy, nephropathy, neuropathy and amputation. Damage to macrovascular circulation can result in heart disease, high blood pressure, and stroke. The development of diabetes among Indians occurs decade earlier than western population. ${ }^{15}$ In developing countries like India, the treatment cost of diabetes in an economically backward family may consume as much as $25 \%$ of the entire income for each person with diabetes. ${ }^{15,16}$ This above information clearly indicates that clinicians must intervene at the pre-diabetic stage to prevent development of diabetes and a host of complications rather than ignoring pre-diabetes.

Insufficient studies on impaired fasting glucose in South Indian population for planning early intervention is the rationale behind this research.

\section{MATERIALS AND METHODS}

The study was cross-sectional in design, conducted on subjects attending medicine outpatient department at Government Vellore Medical College from Vellore, Thiruvannamalai, and Kanchipuram districts. This is done over period of 6 months from April 2016 to September 2016. Totally, 1000 eligible subjects aged above 19 years of both genders were enrolled for the study. Fasting plasma glucose measurement was used as the screening test for the diagnosis of impaired fasting glucose, as recommended by the American Diabetes Association 2016 guidelines. ${ }^{12}$ The fasting plasma glucose was preferred because it was easier to perform, convenient, acceptable to patients and less expensive. Weight, body mass index (BMI), waist circumference (WC), and waist-hip ratio (WHR) of all the participants were recorded.
The subjects with a history of diabetes mellitus, other endocrine abnormalities, patients on long-term corticosteroid therapy, diuretics, and pregnant patients were excluded from the study.

The total body weight was taken by a weighing machine with subjects wearing clothes without shoes. The body mass index was calculated according to the formula: weight in $\mathrm{kg} /$ height in metre ${ }^{2}$. The waist circumference was measured at the level of the last rib after expiration. Hip circumference was measured at the level of maximum diameter of the hip as viewed from the side. The waist-hip ratio was calculated as waist circumference/hip circumference. Data processed and statistically analysed using SPSS trial version software.

A $p$ value of $<0.05$ was considered significant.

\section{RESULTS}

Totally, 985 subjects were studied. This included 496 (50.3\%) males and 489 (49.6\%) females. The prevalence of impaired fasting glucose in the Vellore population attending medicine OPD found to be $15 \%$. Among male subjects, prediabetics were found to be $17 \%$ and among females it was $13 \%$. Among males, the highest percentage of pre-diabetics was found in age group between 60 to 70 years and lowest in age group 20 to 30 years, whereas in females the highest percentage was found in age group above 70 years and lowest in age group of 20 to 30 years (Table I and Fig. 1). Significant difference was found in the prevalence of prediabetics among male and female subjects. Similarly, the prevalence of impaired fasting glucose were higher among both the male and female subjects with BMI $>25$. There is significant difference found in the prevalence of impaired fasting glucose among subjects with BMI above 25 and below 25 . The mean WC among male subjects were 92 and female subjects were 86 and among them only female subjects with increased WC were statistically significant for impaired fasting glucose. The higher WHR in male subjects [1.02] and female subjects [0.9] were significantly related for presence of impaired fasting glucose.

\begin{tabular}{|c|c|c|c|c|c|c|c|c|c|}
\hline \multirow{2}{*}{ Age Group } & \multicolumn{3}{|c|}{ Total Population } & \multicolumn{3}{c|}{ No. of Persons with IFG } & \multicolumn{3}{c|}{ Percentage of IFG } \\
\cline { 2 - 10 } & Male & Female & Total & Male & Female & Total & Male & Female & Total \\
\hline 20 - 30 years & 19 & 13 & 32 & 2 & 1 & 3 & $11 \%$ & $7 \%$ & $9 \%$ \\
\hline 30 - 40 years & 63 & 62 & 125 & 8 & 5 & 21 & $13 \%$ & $8 \%$ & $17 \%$ \\
\hline 40 - 50 years & 124 & 119 & 243 & 20 & 14 & 30 & $16 \%$ & $12 \%$ & $12 \%$ \\
\hline 50 - 60 years & 152 & 143 & 295 & 24 & 16 & 37 & $16 \%$ & $11 \%$ & $13 \%$ \\
\hline 60 - 70 years & 106 & 116 & 222 & 21 & 18 & 38 & $20 \%$ & $16 \%$ & $17 \%$ \\
\hline$>70$ years & 32 & 36 & 68 & 11 & 9 & 20 & $34 \%$ & $25 \%$ & $29 \%$ \\
\hline Total & 496 & 489 & 985 & 86 & 63 & 149 & $17 \%$ & $13 \%$ & $15 \%$ \\
\hline
\end{tabular}

\begin{tabular}{|c|c|c|c|}
\hline Sex & IFG & Normal & P value \\
\hline Male & 86 & 410 & \multirow{2}{*}{$<0.05$} \\
\hline Female & 63 & 426 & \\
\hline
\end{tabular}

\begin{tabular}{|c|c|c|c|}
\hline BMI & IFG & Normal & P value \\
\cline { 1 - 3 }$<25$ & 48 & 437 & \multirow{2}{*}{$<0.05$} \\
\cline { 1 - 3 }$>25$ & 101 & 399 & \\
\hline
\end{tabular}

\begin{tabular}{|c|c|c|c|}
\hline WC-Female & IFG & Normal & P value \\
\hline$<86$ & 56 & 187 & \multirow{2}{*}{$<0.05$} \\
\hline$>86$ & 93 & 153 & \\
\hline
\end{tabular}

\begin{tabular}{|c|c|c|c|}
\hline WC-Male & IFG & Normal & P value \\
\hline$<92$ & 68 & 182 & \multirow{2}{*}{$>0.05$} \\
\hline$>92$ & 81 & 165 & \\
\hline
\end{tabular}




\begin{tabular}{|c|c|c|c|}
\hline WHR-Male & IFG & Normal & P value \\
\hline$<1.02$ & 46 & 206 & \multirow{2}{*}{$<0.05$} \\
\hline$>1.02$ & 103 & 141 & \\
\hline
\end{tabular}

\begin{tabular}{|c|c|c|c|}
\hline WHR-Female & IFG & Normal & P value \\
\hline$<0.9$ & 54 & 193 & \multirow{2}{*}{$>0.05$} \\
\hline$>0.9$ & 95 & 147 & \\
\hline
\end{tabular}

$\mathrm{BMI}=$ Body mass index; $\mathrm{WC}=$ Waist circumference WHR $=$ Waist-hip ratio.

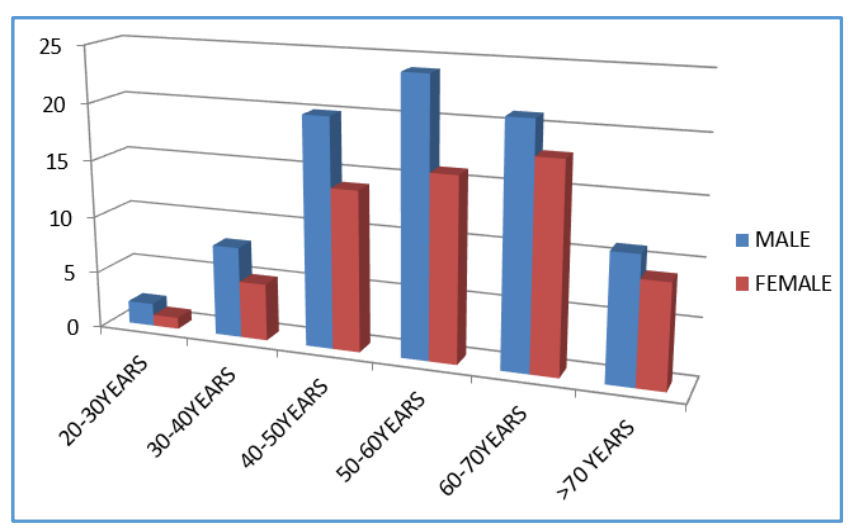

Graph 1

\section{DISCUSSION}

The prevalence of impaired fasting glucose varies among population with different ethnic background. ${ }^{4}$ A study which is conducted in United States shows prevalence of impaired fasting glucose were $26 \%$ in adult population which is much higher when compared with our study [15\%].11 The prevalence of impaired fasting glucose was significantly higher in males, which is similar to our study. In another study done in urban population of Ernakulum district in Kerala by Amrita Diabetes and Endocrine Population Survey [ADEPS] shows prevalence of impaired fasting glucose as $11.2 \%$ which is lower when compared with our study. ${ }^{17}$ In another south Indian study on rural populations of Andhra Pradesh showed prevalence of impaired fasting glucose to be $15.5 \%$ which is similar to our study. ${ }^{18}$

The anthropometric findings in this study were quite similar to our study, there was significant rise in the prevalence of impaired fasting glucose with increasing body mass index. Waist-hip ratio was strongly correlated with prevalence of impaired fasting glucose, just like in our study. The findings of our study were different from "The Kolkata Policeman Study' in which prevalence of impaired fasting glucose was found to be $6.2 \%$ which is much lower on comparing our study. ${ }^{19}$ There was a strong correlation with waist circumference and waist-hip ratio but no significant correlation with body mass index which is also different from our study.

The variation in the results of different studies on impaired fasting glucose is probably due to diversity in culture, lifestyle, ethnic and genetic factors among different population and also rural-urban variations. The notable finding in our study was increase in prevalence of impaired fasting glucose with raising BMI, maybe due to raising the possibility of a higher prevalence of insulin deficient state than previously suspected.

Various studies have demonstrated that diabetes in the Indian population has several unique features. These include a younger age of onset (almost a decade earlier than other populations), a relatively low body mass index, higher intraabdominal fat, high rates of insulin resistance and a high prevalence of insulin deficiency as evidenced by more patients requiring insulin therapy at younger age.
The major limitation of the present study is that it was a hospital-based study and therefore may not represent the true status of the prevalence of impaired fasting glucose (IFG) in the general population.

\section{CONCLUSION}

To conclude, this study revealed that the prevalence of impaired fasting glucose in Vellore population is high (15\%) and is an under-diagnosed condition.

15 out of 100 individuals attending the out-patient department at medicine outpatient clinics have impaired fasting glucose, indicating a need for early detection and intervention in order to effectively prevent the development of diabetes and cardiovascular complications. The traditional risk factors like body mass index, waist-hip ratio are good predictors for development of diabetes mellitus in Vellore and its allied populations but waist circumference alone did not predict the impaired fasting state especially in male populations.

\section{REFERENCES}

1. Sadikot SM, Nigam A, Das S, et al. The burden of diabetes and impaired glucose tolerance in India using the WHO 1999 criteria: prevalence of diabetes in India study (PODIS). Diabetes Res Clin Pract 2004;66(3):301-7.

2. Nathan DM, Davidson MB, Defronzo RA, et al. Impaired fasting glucose and impaired glucose tolerance. Diabetes Care 2007;30(3):753-9.

3. American Diabetes Association. Standards of medical care in diabetes-2012. Diabetes Care 2012;33(Suppl 1):S11-61.

4. Ramaiya KL, Kodali VR, Alberti KG. Epidemiology of diabetes in Asians of the Indian subcontinent. Diab Metabol Rev 1990;6:125-46.

5. Mohan V, Sandeep S, Deepa R, et al. Epidemiology of type 2 diabetes: Indian scenario. Indian J Med Res 2007;125(3):217-30.

6. Mehta SR, Kashyap AS, Das S. Diabetes mellitus in India: the modern scourge. MJAFI 2009;65(1):50-4.

7. Boyle JP, Honeycutt AA, Narayan KM, et al. Projection of diabetes burden through 2050: impact of changing demography and disease prevalence in the U.S. Diabetes Care 2001;24(11):1936-40.

8. Meigs JB, Muller DC, Nathan DM, et al. The natural history of progression from normal glucose tolerance to type 2 diabetes in the Baltimore longitudinal study of aging. Diabetes 2003;52(6):1475-84.

9. Levitan EB, Song Y, Ford ES, et al. Is nondiabetic hyperglycaemia a risk factor for cardiovascular disease? A meta-analysis of prospective studies. Arch Intern Med 2004;164(19):2147-55.

10. Coutinho M, Gerstein HC, Wang Y, et al. The relationship between glucose and incident cardiovascular events. A metaregression analysis published data from 20 studies of 95,783 individuals followed for 12.4 years. Diabetes Care 1999;22(2):233-40. 
11. Liao D, Shofer JB, Boyko EJ, et al. Abnormal glucose tolerance and increased risk for cardiovascular disease in Japanese-Americans with normal fasting glucose. Diabetes Care 2001;24(1):39-44.

12. American diabetic association. Classification and diagnosis of diabetes. Diabetes Care 2016;39 (Suppl1): S13-22.

13. Shaw JE, Zimmet PZ, de Courten M, et al. Impaired fasting glucose or impaired glucose tolerance. What best predicts future diabetes in Mauritius? Diabetes Care 1999;22(3):399-402.

14. Mohan V, Shanthirani CS, Deepa M, et al. Mortality rates due to diabetes in a selected urban south Indian population-the Chennai urban population study (CUPS16). J Assoc Physicians India 2006;54:113-7.

15. Chow CK, Raju PK, Raju R, et al. The prevalence and management of diabetes in rural India. Diabetes Care 2006;29(7):1717-8.
16. Padmini B, Kamalamma N, Patel TG, et al. A communitybased diabetes prevention and management education programme in a rural village in India. Diabetes Care 2008;31(6):1097-104.

17. Menon VU, Kumar KV, Gilchrist A, et al. Prevalence of known and undetected diabetes and associated risk factors in central Kerala-ADEPS. Diabetes Res Clin Pract 2006;74(3):289-94.

18. Ramachandran A, Snehlata C, Mary S, et al. The Indian diabetes prevention programme shows that lifestyle modification and metformin prevent type 2 diabetes in Asian Indian subjects with impaired glucose tolerance (IDPP-1). Diabetolgia 2006;49(2):289-97.

19. Kumar S, Mukherjee S, Mukhopadhyay P. Prevalence of diabetes and impaired fasting glucose in a selected population with special reference to influence of family history and anthropometric measurements-the Kolkata policemen study. J Assoc Physicians India 2008;56: 841-4. 